\title{
Omalizumab updosing for better disease control in chronic spontaneous urticaria patients
}

Emek Kocatürk ${ }^{1}$, Gustavo Deza ${ }^{2}$, Kübra Kızıltaç ${ }^{1}$, Ana M Giménez-Arnau ${ }^{2}$

1 Okmeydanı Training and Research Hospital, Department of Dermatology, Istanbul, Turkey.

2 Department of Dermatology, Hospital del Mar, Universitat Autònoma, Barcelona, Spain

Omalizumab updosing for chronic spontaneous urticaria

Corresponding author: Emek Kocatürk, Okmeydanı Eğitim Araştırma Hastanesi Dermatoloji Kliniği, 34800, Şişli, İstanbul Telephone: 00905052672078, Fax number: 00902122205878, E-mail address: emekozgur@yahoo.com, Key words: urticaria, treatment, omalizumab, updosing, higher doses, real life, Number of tables: 3 , Number of figures: 0

\section{ABSTRACT}

The recommended dose of omalizumab for treatment of chronic spontaneous urticaria (CSU) is 300 $\mathrm{mg}$ /every 4 weeks but there is no recommendation for patients who do not benefit from this dose. Our aim is to present the experiences on the use of higher than the recommended doses of omalizumab in CSU patients and propose a protocol for updosing. This was a retrospective analysis of patients treated with omalizumab for CSU from two-urticaria excellence and reference centers (UCARE centers) Istanbul and Barcelona. The UAS7 and/or the Urticaria Control Test (UCT) were used to monitor response. In Barcelona a step-wise updosing regimen was preferred (450 mg first and then to $600 \mathrm{mg}$ ) while in Istanbul updosing directly to $600 \mathrm{mg}$ was preferred. In Istanbul, $81(88 \%)$ of the patients were treated with $300 \mathrm{mg}$, while $11(12 \%)$ received $600 \mathrm{mg}$ of omalizumab. In Barcelona, $7(8.8 \%), 45(56.3 \%), 17(21.3 \%)$ and $11(13.8 \%)$ of the patients received $150,300,450$ and $600 \mathrm{mg}$ of omalizumab, respectively. Urticaria control was achieved in $82.6 \%$ of patients with $300 \mathrm{mg}$ and in $8.7 \%$ of patients with $600 \mathrm{mg}$ in Istanbul, while it was achieved with $150 \mathrm{mg}$ in $10 \%$, with $300 \mathrm{mg}$ in $48.8 \%$, with $450 \mathrm{mg}$ in $16.3 \%$ and with $600 \mathrm{mg}$ in $6.3 \%$ of the patients in Barcelona. In total, 123 (71.5\%) patients responded to $150-300 \mathrm{mg}$ and $26(15.1 \%)$ to $450-600 \mathrm{mg}$. When $150-300 \mathrm{mg}(\mathrm{n}=123)$ responders were compared with 450-600 mg responders ( $n=26), B M I$ was found higher and pre-oma 
UCT was found lower in patients receiving updosed omalizumab $(p=0.029)$. Baseline data of the patients especially the $\mathrm{BMI}$ and pre-oma UCT might be useful to determine if the patient will require higher doses of omalizumab. We recommend a step-wise approach starting from $450 \mathrm{mg}$ and then updosing to $600 \mathrm{mg}$ in CSU patients who do not respond or partially respond to $300 \mathrm{mg}$ of omalizumab after 12-24 weeks of treatment.

\section{INTRODUCTION}

Chronic spontaneous urticaria (CSU) is characterized by recurrent wheals and/or angioedema for longer than 6 weeks (1). Management is based on avoiding triggering factors and symptomatic treatment (1). Symptomatic treatment consists of a step-wise approach starting with non-sedating antihistamines, updosing antihistamines up to four-fold and then with omalizumab if refractory to antihistamines (1). The introduction of omalizumab to treatment markedly improved the management and provided a safer and effective option for both the patients and their treating physicians. The efficacy of omalizumab in CSU has been established by the results of phase studies including more than 900 patients (2-4). An analysis of these trials evaluated the response patterns and timing of the omalizumab responses and reported a meaningful reduction in symptoms in approximately 60 percent of patients by week 12 whereas approximately 40 percent of patients became asymptomatic by week 12 and about 45 percent by week 24 (5). Real life studies reported complete remission rates ranging from $67-90 \%$ and overall response rate reaching to $97 \%$ with doses given between $150 \mathrm{mg}$ to $600 \mathrm{mg}(6-9)$. The recommended dose of omalizumab for the treatment of CSU is $300 \mathrm{mg}$ / every 4 weeks which is the preferred approach for most of the treating physicians but there is no recommendation for the patients who do not benefit from $300 \mathrm{mg} /$ every 4 weeks after 3 injections.

Our aim was to present the experiences of two urticaria excellence and reference (UCARE) center on the use of higher than the recommended doses of omalizumab in CSU patients who failed to respond to $300 \mathrm{mg} /$ every 4 weeks doses. 


\section{MATERIALS \& METHODS}

This was a retrospective analysis of response rates and safety profile of updosing omalizumab in CSU refractory to $300 \mathrm{mg} /$ every 4 weeks. Ninety-two and 80 CSU patients on follow up from May 2014 to March 2017 enrolled from two-urticaria excellence and reference centers (UCARE centers) (10); Istanbul and Barcelona were analysed. CSU patients receiving at least six administrations of omalizumab were included in the analysis. The weekly urticaria activity score (UAS7) and/or the Urticaria Control Test (UCT) were used to monitor the response. Urticaria control was defined as having UCT $\geq 12$ or well controlled activity as UAS7 $<6$ and complete control and controlled activity was defined as UCT=16 and UAS7=0 $(11,12)$.

In Barcelona a step-wise updosing regimen was preferred (450 mg first and if no response increase to $600 \mathrm{mg}$ ) while in Istanbul updosing directly to $600 \mathrm{mg}$ was preferred. Of note; the treatments were given on a every 4 weeks basis in Barcelona but were given in a two-weekly basis in Istanbul ( 2 patients preferred $600 \mathrm{mg} /$ every 4 weeks). An analysis of demographic data as well as comparison between patients responding to $150-300 \mathrm{mg}$ and $450-600 \mathrm{mg}$ were performed with regard to gender, age, duration of disease, BMI, angioedema, associated chronic inducible urticaria (CINDU), total IgE levels, pre-omalizumab UAS7 (pre-oma UAS7) and pre-omalizumab UCT (pre-oma UCT) scores. We also analysed whether non-responders or partial responders will benefit from updosing. For this; to define the patient as minimally responder the criteria was to have a minimal change of 3 points in UCT and 11 points in UAS7 from baseline to 24 th week of treatment $(12,13)$. Non-responders were the ones without any of the improvements described.

\section{RESULTS}

The demographic characteristics of patients are shown in Table 1. 
In Istanbul $81(88 \%)$ of the patients were treated with $300 \mathrm{mg}$ every 4 weeks, while $11(12 \%)$ received $600 \mathrm{mg}$ of omalizumab (300 mg at two-weeks intervals). In Barcelona, 7 (8,8\%) received $150 \mathrm{mg}$, $45(56.3 \%)$ received $300 \mathrm{mg}, 17(21.3 \%)$ received $450 \mathrm{mg}$ and $11(13.8 \%)$ received $600 \mathrm{mg}$ of omalizumab every 4 weeks injections (Table 2).

Urticaria control was achieved in $82.6 \%$ of patients with $300 \mathrm{mg}$ and in $8.7 \%$ of patients with $600 \mathrm{mg}$ in Istanbul, while it was achieved with $150 \mathrm{mg}$ in $10 \%$, with $300 \mathrm{mg}$ in $48.8 \%$, with $450 \mathrm{mg}$ in $16.3 \%$ and with $600 \mathrm{mg}$ in $6.3 \%$ of the patients in Barcelona. If we consider the total number of CSU patients treated with omalizumab in both centers $(n=172)$ the Urticaria control was achieved by $4,65 \%, 66,86 \%, 7,55 \%$ and $7,55 \%$ of patients at $150,300,450$ and $600 \mathrm{mg}$ doses, respectively. A $13,39 \%$ could not obtain control of the disease in spite of updosing.

At the $12^{\text {th }}$ week of updosing; urticaria control was achieved by $76.4 \%(13 / 17)$ of patients given 450 $\mathrm{mg}$ and by $45.4 \%$ (5/11) of patients given $600 \mathrm{mg}$ in Barcelona while it was achieved by $72.7 \%(8 / 11)$ of patients given $600 \mathrm{mg}$ in Istanbul. In total, among 172 patients, 39 (22,6\%) patients received 450$600 \mathrm{mg}$. Of them; 13 (33.3\%) responded to $450 \mathrm{mg}, 13$ (33.3\%) responded to $600 \mathrm{mg}$ and 13 (33.3\%) did not respond. When we analysed the overall response to omalizumab treatment in both centers we found that; a total of 126 patients received $300 \mathrm{mg}$ and 115 of them were controlled $(91.2 \%$ response rate), a total of 17 patients received $450 \mathrm{mg}$ and 13 were controlled (76.4\% response rate) and a total of 22 patients received $600 \mathrm{mg}$ and 13 were controlled (59\% response rate). Complete control (UCT=16, UAS7=0) was achieved by $67.4 \%$ in Istanbul and $44.7 \%$ in Barcelona. Globally only $8.7 \%$ of patients remained uncontrolled in Istanbul while $18.8 \%$ remained uncontrolled in Barcelona after updosing. If we combine the data from both centres; the percentage of patients that reached well control of the disease at $150-300 \mathrm{mg}$ are $123(71.5 \%)$ and to $450-600 \mathrm{mg}$ are 26 (15.1\%). Complete non responders in spite of updosing were 23 (13.3\%).

\section{Comparison between standard dose responders versus updosing responders}

Among the non-responders, 11 (12\%) patients in Istanbul were up-dosed to $300 \mathrm{mg}$ every 2 weeks, in Barcelona $17(21.3 \%)$ and $11(13.8 \%)$ were updosed to $450 \mathrm{mg}$ and $600 \mathrm{mg}$ every 4 weeks after an average of 6 doses every 4 weeks. Number of injections before updosing ranged between 4-9 $($ mean=7) in Istanbul and 3-11 (mean=5) in Barcelona. When patients who responded to $150-300 \mathrm{mg}$ 
$(n=123)$ were compared with 450-600 mg responders $(n=26)$, duration of disease and angioedema frequency was found higher in patients receiving approved doses $(p=0.003, p=0.03$ and $p=0.000$, respectively) while BMI was higher and pre-oma UCT was lower in patients receiving updosed omalizumab ( $p=0.029)$ (Table 3).

\section{Updosing in patients with minimal response or no response to standard doses}

We could only include 19 patients to define minimally responders who had pre-oma and $24^{\text {th }}$ week UCT or UAS7 data. Classification of the patients according to their responses before updosing revealed four patient categories; 8 patients had a minimal response with omalizumab between 0-24 weeks and benefited from updosing, 2 had a minimal response but did not benefit from updosing, 5 did not have a minimal response but benefited from updosing and 4 did not have a minimal response and did not benefit from updosing.

\section{Adverse effects}

Only minor side effects were reported in 2 of patients receiving $600 \mathrm{mg}$ of omalizumab in both centres (one arthralgia from Istanbul center and one nausea and myalgia from Barcelona centre).

\section{DISCUSSION}

Even though omalizumab $300 \mathrm{mg}$ and $600 \mathrm{mg}$ showed similar efficacy in the phase 2 study (14), experiences from real life pointed to better response rates in some patients with $300 \mathrm{mg}$ given in 2 weeks intervals $(15,16)$. In our study, the analysis of real life data from two urticaria centres showed that updosing omalizumab to $450-600 \mathrm{mg}$ might be needed in some CSU patients treated with omalizumab; approximately $35 \%$ of patients from Barcelona and $12 \%$ of patients from Istanbul received omalizumab higher than approved doses.

Updosing omalizumab (450-600 mg [given $300 \mathrm{mg}$ in 2 weeks intervals or 450-600 mg in 4 weeks intervals]) provided symptom control in approximately $15 \%(8.7 \%$ and $22.6 \%$ from Istanbul and Barcelona, respectively) of the patients who would be otherwise uncontrolled with the approved 
doses. Patients with a higher BMI and lower baseline UCT scores were found to require higher doses to control the disease in our series. In asthma, the recommended dose of omalizumab changes according to the body weight of the patient while a fixed dose regimen is recommended for CSU regardless of the body weight and total IgE levels (17). Since the average BMI of the patients who required updosing was found 30 , our results indicate the necessity of dose adjustment according to the $\mathrm{BMI}$ of the patients; dose enhancement might be required especially in patients with a BMI higher than 30.

The pre-oma UCT was found lower in patients requiring updosing of omalizumab ( 2 vs $4 ; p=0.000$ ). The UCT has been an established instrument to monitor response to treatment or disease control, but UCT as a baseline patient assessment criterion has not been mentioned previously. It was interesting to find that not pre-oma UAS7 but pre-oma UCT defined the need for updosing. This might be attributed to the superiority of this tool which combines the disease activity with the quality of life.

As mentioned above, the updosing regimen differed between the centres; first 450 then $600 \mathrm{mg}$ in Barcelona and directly to $600 \mathrm{mg}$ was preferred in Istanbul. At the 12th week of updosing; urticaria control was achieved by $76.4 \%(13 / 17)$ of patients given $450 \mathrm{mg}$ and by $45.4 \%$ (5/11) of patients given $600 \mathrm{mg}$ in Barcelona while it was achieved by $72.7 \%(8 / 11)$ of patients given $600 \mathrm{mg}$ in Istanbul. In total; from the 39 patients, 13 responded to $450 \mathrm{mg}$ and 13 responded to $600 \mathrm{mg}$ (8 of whom was directly started on $600 \mathrm{mg}$ ). It could be speculated that given the high rate of responders to $450 \mathrm{mg}$, the responders of $600 \mathrm{mg}$ in Istanbul could also be $450 \mathrm{mg}$ responders and the $600 \mathrm{mg}$ nonresponders in Barcelona were the very resistant cases left in the end. The total response rate to updosing was 8/11 (72.7\%) in Istanbul compared to 18/28 (64.3\%) in Barcelona; the difference might arise from 1) severely affected patients in Barcelona 2) two-weekly regimen in Istanbul or 3) higher doses given in Istanbul.

The average number of injections before updosing was 7(4-9) in Istanbul and 5 (3-11) in Barcelona which approximates to 6 when the data is combined. This observation is in line with an expert review which recommends updosing omalizumab in patients not responding to treatment after 24 weeks 
(18). And from the analysis of patients' response patterns before updosing, we might speculate that patients with some response to omalizumab from the beginning might benefit from updosing better but still there were patients who benefited from updosing even without a minimal response from the beginning of treatment. Briefly, presence of minimal response or lack of any response to standard doses of treatment did not predict whether updosing would be beneficial or not.

Our study has several strengths and limitations; first of all this is a retrospective analysis and no preset protocols for updosing has been implemented, the characteristics and severity of patients from the centres are different. But the different protocols from the centres gave the opportunity to compare the advantages and disadvantages of these protocols.

From our clinical experience, we conclude that the baseline data of the patient especially the BMI and pre-oma UCT might be useful to determine if the patient will require higher doses of omalizumab. We recommend a step-wise approach starting from $450 \mathrm{mg}$ and then updosing to 600 mg if no response after 12 weeks of treatment in CSU patients who do not respond or partially respond to $300 \mathrm{mg}$ of omalizumab after $12-24$ weeks of treatment.

Updosing omalizumab provides a safe treatment option for patients who would be otherwise regarded as omalizumab resistant and would be candidate for immunosuppressive treatments. Patients should be given a trial of higher than the standard doses before regarded as omalizumab refractory.

\section{REFERENCES}

1. Zuberbier T, Aberer W, Asero R, Abdul Latiff A.H., Baker D, Ballmer-Weber B, et al. The EAACI/GA²LEN/EDF/WAO Guideline for the Definition, Classification, Diagnosis and Management of Urticaria. The 2017 Revision and Update. Allergy. 2018 Jan 15. doi: 10.1111/all.13397.

2. Kaplan A, Ledford D, Ashby M, Canvin J, Zazzali JL, Conner E, et al. Omalizumab in patients with symptomatic chronic idiopathic/spontaneous urticaria despite standard combination therapy. J Allergy Clin Immunol 2013;132:101-9. 
3. Saini, S.S., Bindslev-Jensen, C., Maurer, M. et al. Efficacy and safety of omalizumab in patients with chronic idiopathic/spontaneous urticaria who remain symptomatic on H1antihistamines: a randomized, placebo-controlled study. J Invest Dermatol. 2015 Mar;135(3):925.

4. Maurer, M., Rosen, K., Hsieh, H.J. et al. Omalizumab for the treatment of chronic idiopathic or spontaneous urticaria. N Engl J Med. 2013; 368: 924-935

5. Kaplan A, Ferrer M, Bernstein JA, Antonova E, Trzaskoma B, Raimundo K, et al. Timing and duration of omalizumab response in patients with chronic idiopathic/spontaneous urticaria. J Allergy Clin Immunol. 2016 Feb;137(2):474-81. doi: 10.1016/j.jaci.2015.08.023.

6. Sussman G, Hebert J, Barron C et al. Real-life experiences with omalizumab for the treatment of chronic urticaria. Ann Allergy Asthma Immunol 2014; 112: 170-174.

7. Metz M, Ohanyan T, Church MK, Maurer M. Omalizumab is an effective and rapidly acting therapy in difficult-to-treat chronic urticaria: a retrospective clinical analysis. J Dermatol Sci. 2014 Jan;73(1):57-62. doi: 10.1016/j.jdermsci.2013.08.011.

8. Ghazanfar MN, Sand C, Thomsen SF. Effectiveness and safety of omalizumab in chronic spontaneous or inducible urticaria: evaluation of 154 patients. $\mathrm{Br} J$ Dermatol. 2016 Aug;175(2):404-6.

9. Giménez-Arnau A, Velasco $M$, Hita JCA, Labrador-Horrillo $M$, and Salvador JFS. Omalizumab: what benefits should we expect? European Journal of Dermatology 2016; 26(4):340-44

10. Maurer, M., Metz, M., Bindslev-Jensen, C., Bousquet, J., Canonica, G. W., Church, M. K., et al. Definition, aims, and implementation of $\mathrm{GA}^{2} \mathrm{LEN}$ urticaria centers of reference and excellence. Allergy 2016: 71; 1210-1218.

11. Stull D, McBride D, Tian H, Gimenez Arnau A, Maurer M, Marsland A, et al. Analysis of disease activity categories in chronic spontaneous/idiopathic urticaria. $\mathrm{Br} J$ Dermatol. 2017 Oct;177(4):1093-1101. 
12. Ohanyan T, Schoepke N, Bolukbasi B, Metz M, Hawro T, Zuberbier T, et al. Responsiveness and minimal important difference of the urticaria control test. J Allergy Clin Immunol. 2017 Dec;140(6):1710-1713.e11.

13. Hawro T, Ohanyan T, Schoepke N, Metz M, Peveling-Oberhag A, Staubach P, et al. The Urticaria Activity Score-Validity, Reliability, and Responsiveness.J Allergy Clin Immunol Pract. 2017 Nov 8. pii: S2213-2198(17)30751-1.

14. Saini S, Rosen KE, Hsieh HJ, Wong DA, Conner E, Kaplan A, et al.A randomized, placebocontrolled, dose-ranging study of single-dose omalizumab in patients with H1antihistamine-refractory chronic idiopathic urticaria. J Allergy Clin Immunol. 2011 Sep;128(3):567-73.e1

15. Clark JJ, Secrest AM, Hull CM, Eliason MJ, Leiferman KM, Gleich GJ, et al.The effect of omalizumab dosing and frequency in chronic idiopathic urticaria. J Am Acad Dermatol. 2016 Jun;74(6):1274-6.

16. Vadasz Z, Tal Y, Rotem M, Shichter-Confino V, Mahlab-Guri K, Graif Y, et al. Omalizumab for severe chronic spontaneous urticaria: Real-life experiences of 280 patients. J Allergy Clin Immunol Pract. 2017 Nov - Dec;5(6):1743-1745.

17. Kopp MV. Omalizumab: anti-Ig E therapy in allergy. Curr Allergy Asthma Rep.2011 Apr;11(2):101-6.

18. Giménez-Arnau AM, Toubi E, Marsland AM, Maurer M. Clinical management of urticaria using omalizumab first licensed biological therapy available for chronic spontaneous urticaria. J Eur Acad Dermatol. 2016 ;30 (Suppl 5) :25-32 


\section{Statements}

\section{Acknowledgements}

None

\section{Statement of Ethics}

Ethics approval has been obtained from both instution's ethics committee for human research.

\section{Disclosures:}

Ana Gimenez Arnau has served as a medical advisor for Uriach Pharma, Genentech, Novartis, FAES, GSK and received research Grants supported by Uriach Pharma, Novartis, Grants from Instituto Carlos III- FEDER and waived educational activities for Uriach Pharma, Novartis, Genentech, Menarini, LEO- PHARMA , GSK, MSD, Almirall. Emek Kocatürk has served as a medical advisor for Novartis and Bayer.

\section{Funding sources:}

None

\section{Author contributions:}

Conceived and designed the study: Emek Kocatürk and Ana Gimenez Arnau. Wrote the manuscript: Emek Kocatürk. Critically reviewed and revised the manuscript: Ana Gimenez Arnau. Agreement with manuscript and conclusions: all Designed the figures and tables: Kübra Kızıltaç, Emek Kocatürk. All authors read and approved the final manuscript.

\section{Table legends:}

Table 1: Demographic characteristics of the patients

Table 2: Data on omalizumab treatment

Table 3: Comparison between 150-300 mg responders and 450-600 mg responders 
Table 1: Demographic characteristics of the patients

\begin{tabular}{|c|c|c|}
\hline & İstanbul (n=92) & Barcelona $(n=80)$ \\
\hline \multicolumn{3}{|l|}{ Gender $_{n, \%}$} \\
\hline Female & $61(66.3 \%)$ & $61(76.3 \%)$ \\
\hline Male & $31(33.7 \%)$ & $19(23.8 \%)$ \\
\hline \multicolumn{3}{|l|}{ Age ${ }_{\text {Mean } \pm S D}$} \\
\hline & $40.45 \pm 12.89$ & $50.85 \pm 14.50$ \\
\hline \multicolumn{3}{|l|}{ Duration of disease } \\
\hline (month) ${ }_{\text {Median (range) }}$ & $12(3-240)$ & $7(3-37)$ \\
\hline \multicolumn{3}{|l|}{ Duration of follow up } \\
\hline (month) & $6-39$ & $6-60$ \\
\hline$B M I_{M e d \pm S D}$ & $26.28 \pm 6.58$ & $27.88 \pm 6.19$ \\
\hline Angioedema $_{n, \%}$ & 63/92 (68.5\%) & $35 / 80$ (43.8\%) \\
\hline 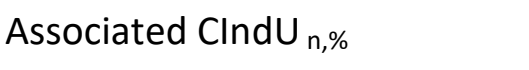 & 26/92 (28.3\%) & $23 / 80(28.8 \%)$ \\
\hline Elevated IgE $(\mathrm{IU} / \mathrm{ml})_{\mathrm{n}, \%}$ & $32 / 78(41 \%)$ & $41 / 66(62.1 \%)$ \\
\hline UAS 7 pre-oma Median (range) & $28.5(7-42)$ & $28(10-42)$ \\
\hline UCT pre-oma Median (range) & $5(0-10)$ & $2(0-13)$ \\
\hline
\end{tabular}

BMI: Body mass index, CINDU: chronic inducible urticaria, Immunosuppressive treatment: previous immunosuppressive treatment, SD:standard deviation 
Table 2: Data on omalizumab treatment

\begin{tabular}{|c|c|c|c|}
\hline & & Istanbul & Barcelona \\
\hline \multirow[t]{4}{*}{ Maximum OMA dose $e_{n, \%}$} & 150 & NA & $7(8.8 \%)$ \\
\hline & 300 & $81(88.0 \%)$ & 45 (56.3\%) \\
\hline & 450 & NA & $17(21.3 \%)$ \\
\hline & 600 & $11(12.0 \%)$ & $11(13.8 \%)$ \\
\hline \multirow{7}{*}{ Dose that controlled $\mathrm{CSU}_{\mathrm{n}, \%}$} & No & & \\
\hline & & $8(8.7 \%)$ & $15(18.8 \%)$ \\
\hline & Control & & \\
\hline & 150 & NA & $8(10 \%)$ \\
\hline & 300 & $76(82.6 \%)$ & $39(48.8 \%)$ \\
\hline & 450 & NA & $13(16.3 \%)$ \\
\hline & 600 & $8(8.7 \%)$ & $5(6.3 \%)$ \\
\hline \multicolumn{2}{|l|}{$450 \mathrm{mg}$ responder (UCT $\geq 12$ at } & & $13 / 17$ \\
\hline & & NA & \\
\hline $12 w)$ & & & (76.4\%) \\
\hline \multicolumn{4}{|l|}{$600 \mathrm{mg}$ responder (UCT $\geq 12$ at } \\
\hline & & $8 / 11(72.7 \%)$ & $5 / 11(45.4 \%)$ \\
\hline \multicolumn{4}{|l|}{$12 w)$} \\
\hline \multirow[t]{3}{*}{ Complete response,$\%$} & & & $34 / 76$ \\
\hline & & $62 / 92(67.4 \%)$ & \\
\hline & & & (44.7\%) \\
\hline \multirow[t]{2}{*}{ Concomitant treatment } & & & $79 / 80$ \\
\hline & & $76 / 90(84.4 \%)$ & \\
\hline with anti $\mathrm{H} 1_{n, \%}$ & & & (\%98.8) \\
\hline
\end{tabular}

UAS7: weekly urticaria activity score, OMA: omalizumab, UCT: urticaria control test

Complete response: $U C T=16$, UAS7=0, NA: not available 
Table 3: Comparison between $150-300 \mathrm{mg}$ responders and $450-600 \mathrm{mg}$ responders

\begin{tabular}{|c|c|c|c|}
\hline & $\begin{array}{c}150-300 \mathrm{mg} \\
(\mathrm{n}=123)\end{array}$ & $\begin{array}{c}450-600 \mathrm{mg} \\
(n=26)\end{array}$ & $\mathbf{p}$ \\
\hline \multicolumn{4}{|l|}{ Gender $_{n, \%}$} \\
\hline Female & $83(67.5 \%)$ & $17(65.4 \%)$ & ${ }^{1} 1.000$ \\
\hline Male & 40 (32.5\%) & $9(34.6 \%)$ & \\
\hline Age & $44.44 \pm 13.44$ & $49.58 \pm 17.60$ & ${ }^{2} 0.170$ \\
\hline $\begin{array}{l}\text { Duration of disease (month) } \\
\text { Median (range) }\end{array}$ & $9(3-240)$ & $6(3-132)$ & ${ }^{3} 0.003 *$ \\
\hline BMI & $26.26 \pm 5.55$ & $30.43 \pm 8.27$ & ${ }^{2} 0.029 *$ \\
\hline Angioedema $_{n} \%$ & $74 / 123(60.2 \%)$ & $9 / 26$ (34.6\%) & ${ }^{1} 0.030 *$ \\
\hline${\text { Associated } \text { CINDU }_{n, \%}}$ & $37 / 123(30.1 \%)$ & $8 / 26$ (30.8\%) & ${ }^{1} 1.000$ \\
\hline Elevated IgE $(\mathrm{IU} / \mathrm{ml})_{\mathrm{n}, \%}$ & $52 / 102(51 \%)$ & $12 / 22(54.5 \%)$ & ${ }^{1} 0.946$ \\
\hline Preoma UAS7 Median (range) & $26(7-42)$ & $34(18-42)$ & ${ }^{3} 0.781$ \\
\hline Preoma UCT Median (range) & $4(0-13)$ & $2(0-9)$ & ${ }^{3} 0.000^{*}$ \\
\hline
\end{tabular}

${ }^{1}$ Chi-Square Test $\quad{ }^{2}$ Continuity (yates) Correction $\quad{ }^{3}$ Mann Whitney U Test

$* p<0.05$

BMI: Body mass index Preoma UCT: pre-omalizumab urticaria control test

Preoma UAS7: pre-omalizumab weekly urticaria activity score CINDU: chronic inducible urticaria 
